\title{
VALORES ORGANIZACIONAIS E SUPORTE SOCIAL NO TRABALHO: PERCEPÇÃO DOS COLABORADORES DO TRIBUNAL DE CONTAS DO ESTADO DE RONDÔNIA ${ }^{1}$
}

\author{
ORGANIZATIONAL VALUES AND SOCIAL SUPPORT AT WORK: PERCEPTION OF THE \\ EMPLOYEES OF THE COURT OF ACCOUNTS FROM RONDONIA STATE
}

\author{
VALORES ORGANIZACIONALES Y APOYO SOCIAL EN EL TRABAJO: \\ PERCEPCIÓN DE LOS EMPLEADOS DEL TRIBUNAL DE CUENTAS DEL ESTADO DE \\ RONDÔNIA
}

James Jonatas Silva, Bacharel em Ciências Contábeis, MBA em Gestão Pública, Bacharel em Ciências Contábeis. Endereço Profissional: Universidade Federal de Rondônia - UNIR, Avenida 02 (Rotary Clube), 3.756 - Setor 10, Jardim Social, CEP: 76.980-000, Vilhena, RO. Telefone: (69) 98493-5842. E-mail: jamesjjsj@gmail.com.

\begin{abstract}
Alexandre de Freitas Carneiro, Mestre em Administração pela Universidade Federal de Rondônia.Endereço Profissional:Universidade Federal de Rondônia - UNIR, Avenida 02 (Rotary Clube), 3.756 - Setor 10, Jardim Social. CEP: 76.980-000, Vilhena, RO.Telefone: (69) 98469-2871, URL da Homepage: www.unir.br. E-mail: alexandrevha95@gmail.com.
\end{abstract}

Flávio de São Pedro Filho, Doutor em Administração pela USP. Endereço Profissional: Universidade Federal de Rondônia - UNIR, Caixa Postal 296, Porto Velho, Estado de Rondônia - CEP 76801-974. URL da Homepage: www.unir.br. E-mail:

flavio1954@gmail.com.

Douglas Vidal, Mestre em Administração pela Universidade Federal de Rondônia.Endereço Profissional: Universidade Guarulhos, Avenida Padre Arlindo Vieira, 1.786, São Paulo SP.CEP 04166-000. Telefone: (11) 99706-11238, URL da Homepage: www.ung.br. E-mail: douglasvidal@yahoo.com.br.

Deyvison Lima de Oliveira, Doutor em Administração pela UFRGS. Endereço Profissional: Universidade Federal de Rondônia, Avenida 02 (Rotary Clube), 3.756 - Setor 10, Jardim Social. CEP: 76.980-000, Vilhena, RO. URL da Homepage: www.unir.br. Telefone: (69) 99216-0191. E-mail: deyvilima@ gmail.com.

\section{RESUMO}

A pesquisa objetiva identificar os valores organizacionais praticados no Tribunal de Contas do Estado de Rondônia, por meio da percepção dos seus colaboradores, e analisar a influência desses valores na percepção do Suporte Social. A pesquisa foi motivada ao se constatar a inexistência de estudos dessas influências na administração pública governamental. A coleta de dados foi realizada através do Inventário de Perfis de Valores Organizacionais (IPVO), elaborado por Oliveira e Tamayo (2004), e da Escala de Percepção de Suporte Social no Trabalho (EPSST), desenvolvida por Gomide Jr., Guimarães e Damásio (2004). Posteriormente, foi realizada uma análise fatorial exploratória para identificar as dimensões

\footnotetext{
${ }^{1}$ Artigo submetido em 06/11/2015, revisado em 02/04/2016, aceito em 22/06/2016 e divulgado em 30/12/2016 pelo Editor João Carlos Hipólito Bernardes do Nascimento, após double blind review.
}

GєCont, v. 3, n. 2, Floriano-PI, Jul-Dez. 2016. 
dos valores organizacionais e do Suporte Social percebidos na organização. Em seguida, aplicou-se a técnica de regressão múltipla para verificar a influência entre as variáveis. Como resultados, identificou-se que os valores prioritários da organização estudada foram: Conformidade, Realização e Tradição. O Suporte Social com maior percepção foi o Suporte Instrumental. Foi confirmado também que os valores Autonomia, Realização e Conformidade possuem influência significativa na percepção do Suporte Social, sendo que o valor Realização teve a maior influência. Como contribuição prática, os resultados podem orientar o desenvolvimento do trabalho e planejamento do setor de Gestão de Pessoas dessa organização de controle externo.

Palavras-chave: Valores Organizacionais; Suporte Social; Comportamento Organizacional.

\section{ABSTRACT}

This research aims at identifying the organizational values practised in the Court of Accounts of the State of Rondonia, through the awareness of its employees, and at analyzing the influence of these values in the perception of the Social support. The research was motivated by the lack of studies of these influences in the governmental public administration. The data collection was carried out through the questionnaires Inventory of Organizational Values Profile (IPVO), developed by Oliveira and Tamayo (2004), and the Social Support Scale at Work (EPSST), developed by Gomide Jr., Guimarães and Damásio ( 2004). Subsequently, an exploratory factor analysis was performed in order to identify the dimensions of the organizational values and of the Social Support perceived in the organization. Then, the multiple regression technique was used in order to verify the influence among the variables. As results, the main values of the organization studied were identified as Conformity, Realization and Tradition. The most expressive Social Support was the Instrumental Support. It was also confirmed that the values Autonomy, Realization and Conformity have significant influence on the perception of the Social Support and the value Realization had the greatest influence. As a practical contribution, the results can guide the development of the work and the planning of the human resources management sector of this external control organization. Keywords: Organizational Values. Social Support. Organizational Behavior.

\section{RESUMEN}

La investigación pretende identificar los valores organizacionales practicada en el Tribunal de Cuentas del Estado de Rondônia, por medio de la percepción de sus empleados, y analizar la influencia de estos valores en la percepción de apoyo social. La investigación fue motivada para señalar que la falta de estudios de estas influencias en la administración pública gubernamental. La recolección de datos se llevó a cabo mediante el Inventario de perfiles de valores organizacionales (IPVO), elaborado por Oliveira y Tamayo (2004), y la escala de percepción de apoyo social en el trabajo (EPSST), desarrollado por Gomide Jr., Guimarães y Damásio (2004). Posteriormente, se realizó análisis factorial exploratorio para identificar las dimensiones de los valores de la organización y el apoyo social percibido en la organización. A continuación, se aplica la técnica de regresión múltiple para comprobar la influencia entre las variables. Como resultado, se identificó que los valores prioritarios de la organización estudiados fueron: la conformidad, la realización y la tradición. El apoyo social con mayor percepción fue el apoyo instrumental. También se confirmó que los valores de la autonomía, la realización y la conformidad tienen influencia significativa sobre la percepción del apoyo social, siendo que el valor realización ha tenido mayor influencia. Como contribución práctica, los resultados pueden guiar el desarrollo de la labor y el sector de la planificación de la gestión de personas de esa organización de control externo.

Palabras claves: Valores Organizacionales. Apoyo social. Comportamiento Organizacional.

GєCont, v. 3, n. 2, Floriano-PI, Jul-Dez. 2016. 


\section{INTRODUÇÃO}

E ste estudo se enquadra na área de organizações públicas com foco em Gestão de Pessoas, especificamente em valores organizacionais e suporte social no trabalho. Tamayo (1998) afirma que a satisfação no trabalho encontra sua fonte principal na natureza, no grupo, nas condições e no clima em que ele é realizado. Nesse contexto, os valores orientam o funcionamento e a vida da organização, o comportamento dos colaboradores motiva a obtenção de metas e objetivos, determina as formas de interpretar os comportamentos e eventos organizacionais, e influenciam o ambiente e tomada de decisões organizacionais (TAMAYO, 2005).

Os membros de uma instituição, durante as relações de trabalho, desenvolvem crenças e comportamentos influenciados pelos valores da organização. Essas crenças sinalizam para o suporte social, que, segundo Cobb (1976), pode ser compreendido por meio de informações que estão organizadas em três classes de crenças por parte do sujeito: crenças de que são amados e existem pessoas preocupadas com ele; crenças de que são apreciados e valorizados e, por último, de que pertencem a uma rede social. Assim, o suporte social pode ser entendido como um conceito multidimensional, que inclui os recursos materiais e também psicológicos, aos quais as pessoas têm acesso por meio das redes sociais (GOMIDE JR.; SIQUEIRA, 2008).

Estudos já realizados destacaram a importância do Suporte Social para atenuar os efeitos de eventos estressores sobre a saúde e reduzir o risco de doenças (COHEN; MCKAY, 1984).A pesquisa tem relevância tanto pela abordagem exploratória, quanto pelo desenvolvimento organizacional e aumento da qualidade de vida dos colaboradores. Além disso, foi realizado um levantamento nas bases de dados dos Periódicos da Capes, Scientific Periodicals Electronic Library (Spell) e Scientific Eletronic Library Online (Scielo), com as palavras chaves "Valores Organizacionais", "Suporte Social" e "Administração Pública", e não foram encontrados trabalhos que verificassem a influência dos valores organizacionais na percepção do Suporte Social em entidades da Administração Pública. Estudos, como os de Andrade e Estivalete (2010) e de Estivalete, Andrade, Costa e Gomes (2012), trataram do tema, mas nos setores Bancário, público e privado. Os autores objetivaram compreender a influência dos valores organizacionais sobre a percepção de suporte no trabalho, a partir da perspectiva dos funcionários do Setor Bancário Público Estadual e Federal. No entanto, constatou-se a inexistência de estudos na Administração Pública Governamental.

O presente trabalho tem por objetivo identificar os valores organizacionais praticados no Tribunal de Contas do Estado de Rondônia, por meio da percepção dos seus colaboradores, e analisar a influência desses valores na percepção do Suporte Social. Para se alcançar o objetivo do artigo, no segundo tópico, serão revistos conceitos dos valores organizacionais e do Suporte Social no trabalho. No terceiro, será apresentado o método da pesquisa e sua abrangência. No seguinte, serão expostos o resultado da pesquisa e sua discussão. Por fim, serão expostas as considerações finais, inclusive as limitações deste estudo e recomendações para os novos.

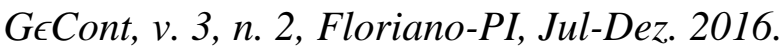




\section{VALORES ORGANIZACIONAIS E SUPORTE SOCIAL NO TRABALHO}

\subsection{VALORES ORGANIZACIONAIS}

Ferreira (2013) estabelece uma metáfora da cultura organizacional, equiparando-a a um iceberg,onde, na superfície, estão os aspectos perceptíveis e, abaixo da superfície, a cultura latente, cujos aspectos informais são: percepções, atitudes, sentimentos, valores, interações e normas grupais. A cultura é um fator determinante do desempenho individual, da satisfação e produtividade da organização, sendo esta última definida pelos valores compartilhados pelas pessoas em um grupo (TAMAYO; MENDES; PAZ, 2000).

Schwartz (1992), na construção da teoria dos valores pessoais, identificou os valores fundamentais que todas as pessoas em todas as culturas reconhecem. No contexto das organizações, os valores são formados a partir dos valores da sociedade e de seus membros (TAMAYO, 2008). Para as organizações, segundo Tamayo, os valores constituem um elemento fundamental e necessário para dar identidade coletiva a um grupo de pessoas e colocá-las a trabalhar em torno de ideias comuns, permitindo e favorecendo o máximo de desenvolvimento do talento do indivíduo. Para Bergue (2014), o componente essencial na criação de valor público (valor para a sociedade), na grande maioria dos processos de trabalho, são as pessoas.

Ao definirem os valores organizacionais, Tamayo e Gondim (1996) enfatizam alguns elementos nesse contexto. Os aspectos cognitivos são crenças valorizadas e enfatizadas na vida organizacional, que proporcionam conhecimento da realidade e respostas prontas e privilegiadas a problemas organizacionais; o aspecto motivacional expressa interesses e desejos tanto dos indivíduos, quanto da coletividade e, por conseguinte, os valores têm a função de orientar a vida da empresa e guiar os comportamentos de seus membros, delimitando sua forma de pensar, agir e sentir; a hierarquização dos valores implicam preferência e distinção entre o importante e o secundário.

Conforme destacam Oliveira e Tamayo (2004), os valores possuem funções importantes dentro das organizações, sendo a primeira a de criar entre os colaboradores modelos mentais semelhantes, relativos ao funcionamento e à missão da organização, e a segunda, a construção da identidade social da organização. Os autores destacam ainda o papel importante que os valores desempenham no alcance dos objetivos organizacionais e no atendimento das necessidades dos indivíduos.

$\mathrm{Na}$ literatura científica, pesquisadores desenvolveram instrumentos para identificar e medir os valores organizacionais. Oliveira e Tamayo (2004), tomando como base a similaridade motivacional entre os valores pessoais e organizacionais, construíram o Inventário de Perfis de Valores Organizacionais (IPVO), baseando-se, do ponto de vista teórico, nos modelos dos valores pessoais propostos por Schwartz (1992). O IPVO é composto por 48 itens distribuídos em oito fatores, conforme mostra o Quadro 1: 
Quadro 1 - Fatores IPVO e Metas dos Valores Organizacionais

\begin{tabular}{|l|l|}
\hline Fatores & Metas \\
\hline Autonomia & $\begin{array}{l}\text { Oferecer des afios e variedade no trabalho, es timular a curiosidade, a criatividade e a } \\
\text { inovação. }\end{array}$ \\
\hline Bem-estar & Promover a satisfação, o bem-estar e a qualidade de vida no trabalho. \\
\hline Realização & Valorizar a competência e o sucesso dos trabalhadores. \\
\hline Domínio & Obter lucros, ser competitiva e dominar o mercado. \\
\hline Prestígio & $\begin{array}{l}\text { Ter prestígio, ser reconhecida e admirada por todos, oferecer produtos e serviços } \\
\text { Satisfatórios para os clientes. }\end{array}$ \\
\hline Tradição & Manter a tradição e respeitar os costumes da organização. \\
\hline Conformidade & $\begin{array}{l}\text { Promover a correção, a cortesia e as boas maneiras no trabalho e o respeito às normas } \\
\text { da organização. }\end{array}$ \\
\hline $\begin{array}{l}\text { Preocupação com a } \\
\text { Coletividade }\end{array}$ & $\begin{array}{l}\text { Promover justiça e a igualdade na organização, bem como a tolerância, a sinceridade e } \\
\text { a honestidade. }\end{array}$ \\
\hline
\end{tabular}

Fonte: Adaptado de Oliveira e Tamayo (2004, p. 137)

Deal e Kennedy (1982) ressaltam que, como essência da filosofia da empresa para alcançar o sucesso, os valores proporcionam um senso de direção comum a todos os empregados e orientam comportamentos para o alcance de objetivos.

Os trabalhadores possuem uma visão mais clara dos valores que predominam dentro da organização, pois vivem na prática a realidade organizacional. Como afirma Tamayo (2008), os valores compartilhados pelos membros da organização estão imbricados nas práticas organizacionais e influenciam inevitavelmente o comportamento de gestores e empregados. Corroborando essas afirmações, Ferreira (2013) defende que os valores compartilhados são aqueles importantes que definem a razão pela qual as coisas são feitas.

Os valores constituem, assim, padrões coletivos que orientam o cotidiano da organização. Portanto, para adequar o comportamento dos empregados às metas organizacionais, aumentar a produtividade e possuir bom relacionamento entre seus membros e a organização, afirma Tamayo (2008), a organização precisa criar por meio dos seus valores, um ambiente que atenda às aspirações fundamentais do ser humano de se realizar e ser feliz. Para isso, torna-se importante também a atenção ao suporte social no trabalho.

Vieira e Gomes (2013) buscaram identificar e relatar os valores organizacionais em uma organização pública, um Campus da Universidade Federal do Rio Grande do Norte. Os resultados, de acordo com esses autores, revelaram que os valores organizacionais, de maior importância para a instituição pesquisada, estão relacionados à hierarquia e, os valores que detêm menor importância estão relacionados a igualitarismo. Ao concluírem, sugeriram uma reflexão sobre o ambiente de trabalho com o intuito de aflorar comportamentos mais afetivos que possibilitem maior comprometimento, satisfação e envolvimento dos servidores

\subsection{SUPORTE SOCIAL NO TRABALHO}

Ao se relacionar no ambiente social, toda atenção, ajuda ou auxílio recebido de outrem pelo indivíduo é entendido como Suporte Social (GOMIDE JR.; SIQUEIRA, 2008). Estudos realizados inicialmente nesse campo evidenciaram que os laços ou redes sociais possuem influência na manutenção da saúde e do bem-estar. Cobb (1976) identificou influências da percepção do suporte social na proteção contra efeitos causados pelo estresse. $\mathrm{O}$ autor definiu ainda, suporte social como sendo informações que levam o indivíduo a acreditar que é amado, querido e estimado e membro de uma rede de obrigações sociais mútuas.

O indivíduo, ao se integrar e participar de uma rede social, acredita que pode receber um conjunto de sensações benéficas que contribuem para sua saúde, como sentimento de 
segurança e estabilidade na vida, sentimento de autoestima e autoconfiança, que geram como resultado bem-estar psicológico (RODRIGUEZ;COHEN, 1998).

Siqueira e Pandovam (2008) propõem que "bem-estar" é, no trabalho, um conceito concebido por três principais componentes: a satisfação, o envolvimento e o comprometimento organizacional efetivo. Mencionam ainda que o bem-estar pode ser entendido como um construto psicológico integrado por vínculos afetivos positivos com o trabalho e com a organização.

Gomide Jr. e Siqueira (2008) afirmam que o Suporte Social é um conceito multidimensional que inclui recursos materiais e psicológicos, aos quais os indivíduos têm acesso por meio das redes sociais. Destacam ainda que as dimensões amplamente estudadas do Suporte Social são: suporte emocional, suporte instrumental e suporte informacional. O suporte instrumental consiste na prestação de apoio material, como ajuda financeira ou auxílio na realização de tarefas diárias. O suporte informacional refere-se ao fornecimento de informações que auxiliam o indivíduo a lidar com dificuldades do cotidiano e orientam na resolução de problemas. Já o suporte emocional são expressões que provocam no indivíduo sentimento de empatia, cuidado, tranquilidade e confiança (RODRIGUEZ; COHEN, 1998).

De acordo com Seeman (2008), dentre as dimensões do suporte social, o suporte emocional é o mais percebido durante as relações no contexto social e também nas relações de trabalho em que os indivíduos estão inseridos, contribuindo para o bem-estar psíquico, podendo reduzir sentimentos de insatisfações e gerar aumento da estabilidade emocional.

Nesse sentido, o suporte social gera efeitos positivos tanto para quem recebe, quanto quem oferece o apoio. Nota-se, ainda, a importância da percepção das redes e do Suporte Social para desenvolvimento de programas e políticas de Saúde, que podem ser desenvolvidos no ambiente de trabalho (CHOR et al., 2001).

Cohen (2004) ressalta que o suporte social tem papel importante no fornecimento de recursos psicológicos e materiais destinados a aumentar a capacidade do indivíduo de lidar com os efeitos do estresse e promover comportamentos saudáveis.

A partir das pesquisas já realizadas e baseando-se nos pressupostos de Rodriguez e Cohen (1998), Gomide Jr., Guimarães e Damásio (2004) construíram e validaram a Escala de Suporte Social no Trabalho (EPSST), com o intuito de verificar a percepção dos empregados acerca do Suporte Social oferecido pelas empresas onde trabalham. O instrumento EPSST é formado por uma escala multidimensional com três fatores, conforme o Quadro 2.

\section{Quadro 2 - Fatores e definicões do EPSST}

\begin{tabular}{|l|l|}
\hline Nomes dos fatores & Definições \\
\hline $\begin{array}{l}\text { Suporte social } \\
\text { informacional no } \\
\text { trabalho }\end{array}$ & $\begin{array}{l}\text { Crenças do empregado de que a organização empregadora pos sui uma rede de } \\
\text { comunicações comum que veicula informações precis as e confiáveis . }\end{array}$ \\
\hline $\begin{array}{l}\text { Suporte social } \\
\text { emocional no trabalho }\end{array}$ & $\begin{array}{l}\text { Crenças do empregado de que na organização empregadora existem pes oas em quem } \\
\text { ge pos sa confiar, que se mostram preocupadas umas com as outras, se valorizam e se }\end{array}$ \\
\hline $\begin{array}{l}\text { Suporte social } \\
\text { instrumental (material) } \\
\text { no trabalho }\end{array}$ & $\begin{array}{l}\text { Crenças do empregado de que a organização empregadora o provê de insumos } \\
\text { materiais, financeiros, técnicos e gerenciais. }\end{array}$ \\
\hline
\end{tabular}

Fonte: Adaptado de Gomide Jr. e Siqueira (2008)

O Suporte Social no trabalho, conforme Gomide Jr., Guimarães e Damásio (2004), refere-se à crença global dos colaboradores de que a organização empregadora oferece os três tipos de suportes (informacional, emocional, instrumental) necessários à execução dos trabalhos. Por meio do instrumento EPSST, é possível avaliar se o trabalhador percebe a 
oferta dos três tipos de Suporte Social no ambiente de trabalho, tornando possível analisar seus impactos no comportamento dos colaboradores.

\section{MÉTODO}

Para a coleta de dados, a pesquisa exploratória foi realizada por meio do método survey. A população é representada pelos colaboradores do Tribunal de Contas do Estado de Rondônia (TCE-RO), composta por cargos efetivos, comissionados, estagiários de nível médio e superior, totalizando 601 servidores. No cálculo da amostra, e de acordo com Martins e Theóphilo (2009), considerando um risco de erro de 5\% e o nível de confiança de $95 \%$, calculou-se o equivalente a 234 respondentes.

Dois questionários foram disponibilizados online, encaminhados via e-mail aos colaboradores. Ambos os instrumentos foram elaborados com escala de Likert cinco pontos. $\mathrm{Na}$ coleta dos dados, foram utilizados os instrumentos: Inventário de Perfis de Valores Organizacionais (IPVO) adaptado para setor público, e Escala de Percepção de Suporte Social no Trabalho (EPSST), adaptado pelos autores. O retorno foi de 74 questionários, o que representou aproximadamente $32 \%$ da amostra - acima de $25 \%$, que corresponde à média de devolução, de acordo com Marconi e Lakatos (2009). O pré-teste foi realizado com dois servidores de uma Secretaria Regional do TCE-RO, e identificou melhorias a serem realizadas no instrumento de pesquisa.

O IPVO construído e validado por Oliveira e Tamayo (2004) é originalmente distribuído em 48 itens, em oito fatores: Autonomia; Bem-estar; Realização; Domínio; Prestígio; Conformidade; Tradição; e Preocupação com a Coletividade. Ao adaptar o questionário, foram removidos dez itens que representam dois fatores. Dessa maneira, ficaram 38 itens que formam os seguintes fatores: Autonomia; Bem-estar; Realização; Conformidade; Tradição; e Preocupação com a Coletividade.

O EPSST desenvolvido por Gomide Jr., Guimarães e Damásio (2004) é composto por 18 questões que representam uma escala multidimensional com três fatores percebidos no trabalho: suporte informacional, suporte emocional e suporte instrumental.

Após a coleta dos dados, através do software de análises estatísticas IBM SPSS (Statistical Package for the Social Sciences), versão 20, foi realizada a validação dos dados e a aplicação dos testes. Primeiramente, foi realizada a análise da percepção de instrumentos separadamente. Após isso, foram feitos testes de relação entre as variáveis dos valores organizacionais (variáveis independentes) e do Suporte Social (variáveis dependentes), a fim de se verificar vínculos e dependência entre tais fatores.

Como a entidade pesquisada é uma entidade do setor público, que possuiu particularidades e diferenças do setor privado, adaptou-se o questionário original IPVO para que se adequasse melhor à realidade pesquisada. Tais procedimentos já foram realizados na literatura de Teixeira (2008), que adaptou apenas alguns itens do IPVO para adequar os valores organizacionais no Terceiro Setor. Originalmente, a escala é composta por 8 fatores e 48 itens (variáveis), que formam suas dimensões. Ao adaptar-se o questionário, foram retirados dez itens que formavam os fatores Domínio e Prestígio, ambos relacionados a poder e lucratividade, o que tem pouca relevância no setor público. Conforme Teixeira (2008), ainda são necessárias pesquisas nas entidades sem fins lucrativos visando ao aperfeiçoamento da escala de valores nessas organizações.

A Figura 1 apresenta o desenho da pesquisa. 
Figura 1 - Desenho da pesquisa

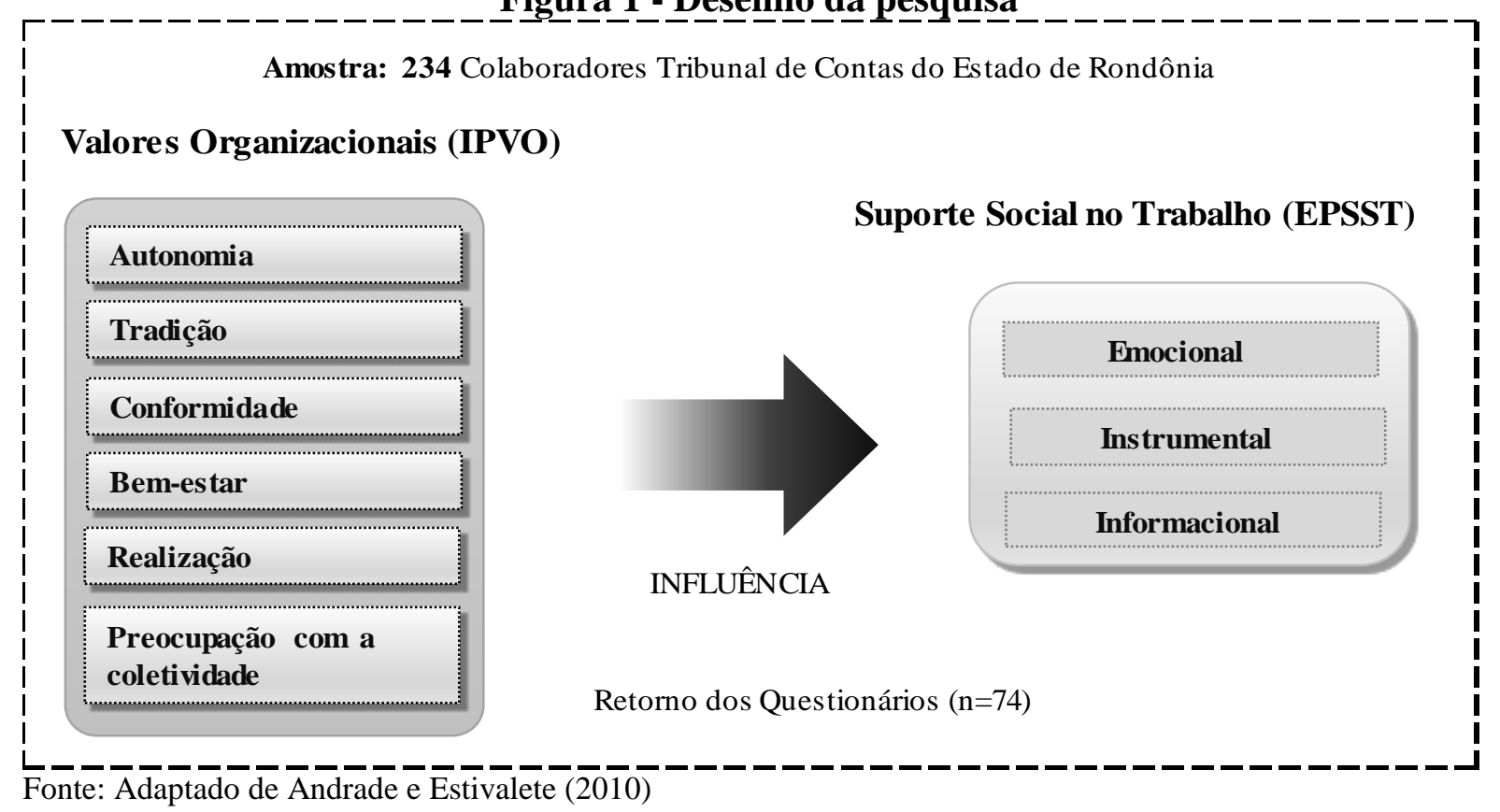

$\mathrm{Na}$ análise multivariada dos dados, empregou-se a análise fatorial exploratória e a regressão múltipla. A análise fatorial exploratória, segundo Hair Jr. et al.(2009), tem como propósito definir uma estrutura inerente às variáveis duma análise, de maneira a agrupá-las em fatores de acordo com suas correlações. De acordo com Corrar, Paulo e Dias Filho (2011), um dos seus principais objetivos é tentar descrever um conjunto de variáveis originais por meio da criação de um número menor de fatores. Para Figueiredo Filho e Silva Jr. (2010), a análise fatorial é uma maneira adequada de mensurar fenômenos que não podem ser diretamente observados. Já a regressão múltipla, segundo Hair Jr. et al. (2009), é uma técnica estatística que pode ser usada para analisar a relação entre uma única variável dependente (critério) e independentes (preditoras).

\section{APRESENTAÇÃO E ANÁLISE DOS RESULTADOS}

Da amostra de 234 questionários, obteve-se o retorno de 74 respondentes, sendo $54,5 \%$ homens e $45,95 \%$ mulheres, com idade média entre 25 e 35 anos. Em relação à escolaridade, 2,70\% possuem Pós-Graduação, Mestrado ou Doutorado, 39,19\%, Especialização, 21,62\%, Superior Completo, 31,08\%, Superior Incompleto e 5,41\%, Ensino Médio. Ao se analisar o tempo de trabalho na organização, observou-se que 27,03\% possuem mais de dez anos de instituição, $24,32 \%$, entre cinco e dez anos, $10,81 \%$, entre três e cinco anos, $4,5 \%$, entre dois a três anos e $33,78 \%$, menos de 2 anos.

\subsection{PERCEPÇÃO DOS VALORES ORGANIZACIONAIS}

Para analisar os dados coletados através do IPVO (Inventário de Perfis de Valores Organizacionais), aplicou-se a análise fatorial exploratória utilizando as 38 variáveis do questionário de maneira a agrupá-las em fatores. Para a extração dos fatores, optou-se pelo método dos componentes principais e rotação pelo método ortogonal de Varimax. Subsequentemente, foi realizado o teste de esfericidade de Bartlett e o teste de Kaiser-MeyerOlklin (KMO) a fim de se verificar a adequabilidade da aplicação da análise fatorial. $\mathrm{O}$ resultado expresso no teste KMO foi de 0,862 , demostrando um bom grau de ajuste para a aplicação da análise fatorial. Já o teste esfericidade de Bartlett apresentou um resultado 
significativo (sig 0,000). Ao se realizar a análise individual das variáveis através da Medida de Adequação da Amostra (MSA), foi necessário realizar a exclusão de três variáveis com valores abaixo do mínimo aceitável de 0,5. As correlações anti-imagem indicaram que a matriz de correlação é perfeitamente adequada para a aplicação da análise fatorial.

Após esses procedimentos, foram verificados os valores das comunalidades de cada variável. Desta vez, foi necessária a exclusão de cinco variáveis que apresentaram valores abaixo do adequado. Assim, todas as outras variáveis ficaram com valores acima de 0,5. Pela análise de componentes principais, observou-se que $72,13 \%$ da variância total pode ser explicada por seis fatores. O mesmo também pode ser observado realizando a análise dos autovalores (eingenvalues) maiores que 1,0. O primeiro fator explicou 47,31\% da variância total.

Em seguida, aplicou-se o teste de confiabilidade Alfa de Cronbach aos fatores extraídos com o objetivo de realizar um diagnóstico da consistência interna desses fatores. Segundo Hair Jr. et al. (2009), o resultado desse teste apresenta coeficientes que variam de 0 a 1 , sendo que o limite mínimo aceito é de 0,7 , podendo diminuir para 0,6 em pesquisa exploratória. Em primeira análise, todos os seis fatores apresentaram alfas superiores a 0,7, indicando um bom índice de confiabilidade. Apesar de valores satisfatórios para os alfas, foi utilizado esse piso como critério, a priori, para a determinação do número dos fatores.

De acordo com Hair Jr. et al. (2009), esse critério é aplicado quando o pesquisador já sabe quantos fatores extrair antes de empreender a análise fatorial, sendo útil quando se testa uma teoria ou hipótese e também quando se tenta repetir o trabalho de outro pesquisador. Dois dos seis fatores extraídos possuíam variáveis que representam apenas um fator quando comparadas ao modelo original proposto por Oliveira e Tamayo (2004). Dessa maneira, ficaram definidos cinco fatores. Outra observação foi a dispersão dos itens do valor "Preocupação com a Coletividade" do IPVO, o que impossibilitou que ele fosse representado por fator único. Assim, suas variáreis ficaram divididas entre os fatores mais representativos e sua denominação não foi atribuída a nenhum novo fator obtido pela análise.

Após a realização de todos os procedimentos da análise fatorial, obtiveram-se cinco fatores ou dimensões que formam os valores organizacionais percebidos pela organização pesquisada. Todos os fatores apresentaram boa consistência interna através do teste Alfa de Cronbach, sendo que os Fatores 1 e 2 obtiveram coeficientes acima de 0,9, os Fatores 3 e 4, acima de 0,8 e o Fator 5, acima de $0,7$.

Através da Tabela 1, pode-se realizar a análise detalhada das variáveis componentes de cada fator criado, possibilitando a sua comparação com os valores originais identificados por Oliveira e Tamayo (2004). O nome de cada fator foi atribuído de acordo com a predominância das variáveis que representam os valores originais, considerando também os valores das cargas fatoriais, que, segundo Hair Jr. et al. (2009), correspondem à correlação de cada variável ao fator e servem para interpretar o papel que cada variável tem na definição de cada fator.

GєCont, v. 3, n. 2, Floriano-PI, Jul-Dez. 2016. 
Tabela 1 -Composição dos fatores com as respectivas cargas obtidas com a rotação Varimax e fatores originais correspondentes

\begin{tabular}{|c|c|c|c|c|}
\hline Fator & Variáveis & Fator IPVO & Carga & Alpha \\
\hline \multirow{8}{*}{$\begin{array}{c}\text { Fator } 1 \text { - } \\
\text { Realização }\end{array}$} & A organização procura aperfeiçoar constantemente. & Autonomia & 0,753 & \multirow{8}{*}{0,923} \\
\hline & $\begin{array}{l}\text { A organização gosta de servidores que mostram suas } \\
\text { habilidades. }\end{array}$ & Realização & 0,751 & \\
\hline & $\begin{array}{l}\text { A organização valoriza servidores que buscam realização } \\
\text { no trabalho. }\end{array}$ & Autonomia & 0,654 & \\
\hline & A organização acredita no valor da honestidade. & $\begin{array}{l}\text { Preocupação com a } \\
\text { coletividade }\end{array}$ & 0,623 & \\
\hline & A organização valoriza a competência. & Realização & 0,609 & \\
\hline & Na organização, é importante que os servidores conheçam & Realização & 0,585 & \\
\hline & A organização acredita nos servidores curiosos. & Autonomia & 0,525 & \\
\hline & A organização acha importante ser competente. & Realização & 0,489 & \\
\hline \multirow{7}{*}{$\begin{array}{l}\text { Fator } 2- \\
\text { Autonomia }\end{array}$} & A organização incentiva o servidor a ser criativo. & Autonomia & 0,771 & \multirow{7}{*}{0,909} \\
\hline & Para a organização é importante ser criativa. & Autonomia & 0,706 & \\
\hline & $\begin{array}{l}\text { A organização acredita que a pessoa deve ser honesta em } \\
\text { qualquer situação. }\end{array}$ & $\begin{array}{l}\text { Preocupação com a } \\
\text { Coletividade }\end{array}$ & 0,692 & \\
\hline & $\begin{array}{l}\text { Para a organização todas as pessoas devem ser tratadas } \\
\text { com igualdade. }\end{array}$ & $\begin{array}{l}\text { Preocupação com a } \\
\text { coletividade }\end{array}$ & 0,686 & \\
\hline & $\begin{array}{l}\text { A organização estimula os servidores a enfrentarem } \\
\text { desafios. }\end{array}$ & Autonomia & 0,66 & \\
\hline & É importante para a organização ajudar seus servidores. & Bem-Estar & 0,511 & \\
\hline & $\begin{array}{l}\text { A organização incentiva o sucesso profissional dos } \\
\text { servidores. }\end{array}$ & Autonomia & 0,479 & \\
\hline \multirow{6}{*}{$\begin{array}{l}\text { Fator } 3- \\
\text { Tradição }\end{array}$} & $\begin{array}{l}\text { O comportamento do servidor deve mostrar respeito aos } \\
\text { costumes. }\end{array}$ & Tradição & 0,847 & \multirow{6}{*}{0,875} \\
\hline & A organização preserva os costumes antigos. & Tradição & 0,781 & \\
\hline & A tradição é uma marca da organização. & Tradição & 0,749 & \\
\hline & $\begin{array}{l}\text { Para a organização é importante que todas as pessoas } \\
\text { sejam tratadas de maneira justa. }\end{array}$ & $\begin{array}{l}\text { Preocupação coma } \\
\text { coletividade }\end{array}$ & 0,618 & \\
\hline & A organização considera a lealdade importante. & $\begin{array}{l}\text { Preocupação com a } \\
\text { coletividade }\end{array}$ & 0,528 & \\
\hline & A organização acredita que a cortesia é importante. & Conformidade & 0,524 & \\
\hline \multirow{5}{*}{$\begin{array}{l}\text { Fator } 4 \text { - } \\
\text { Bem-Estar }\end{array}$} & $\begin{array}{l}\text { A organização preocupa-se com a qualidade de vida dos } \\
\text { servidores. }\end{array}$ & Bem-Estar & 0,802 & \multirow{5}{*}{0,872} \\
\hline & $\begin{array}{l}\text { Para a organização é importante manter clubes destinados } \\
\text { ao lazer dos servidores. }\end{array}$ & Bem-Estar & 0,768 & \\
\hline & $\begin{array}{l}\text { A organização oferece oportunidades de diversão aos } \\
\text { servidores. }\end{array}$ & Bem-Estar & 0,738 & \\
\hline & $\begin{array}{l}\text { A organização propõe atividades que dão prazer ao } \\
\text { servidor. }\end{array}$ & Bem-Estar & 0,633 & \\
\hline & $\begin{array}{l}\text { A organização acha importante ser fiel aos seus } \\
\text { servidores e juris dicionados. }\end{array}$ & $\begin{array}{l}\text { Preocupação com a } \\
\text { coletividade }\end{array}$ & 0,489 & \\
\hline \multirow{3}{*}{$\begin{array}{c}\text { Fator } \mathbf{5}- \\
\text { Conformidade }\end{array}$} & $\begin{array}{l}\text { O respeito à hierarquia faz parte das tradições desta } \\
\text { organização. }\end{array}$ & Conformidade & 0,816 & \multirow{3}{*}{0,731} \\
\hline & A organização acredita que as regras são importantes. & Conformidade & 0,706 & \\
\hline & $\begin{array}{l}\text { A organização acha importante manter modelos de } \\
\text { comportamentos definidos. }\end{array}$ & Conformidade & 0,619 & \\
\hline
\end{tabular}

Fonte: Dados da pesquisa

O fator 1, que ficou denominado de "Realização", foi formado pelas assertivas relacionadas aos valores Realização e Autonomia do IPVO. Esse fator é entendido como a valorização do sucesso e competência dos colaboradores. Em pesquisas anteriores, Andrade e Estivalete (2010) também afirmam que foram realizados agrupamentos de variáveis 
divergentes dos fatores originais da escala IPVO ao se realizar a aplicação da análise fatorial exploratória. O fator 2, denominado "Autonomia", que possui a maioria das variáveis associadas à mesma dimensão do modelo original, refere-se à oportunidade de desafios e de variedade no trabalho, além estímulo à curiosidade, criatividade e inovação. $O$ fator 3 , "Tradição", formado pelas variáveis predominantes associadas ao mesmo fator do modelo original, evidencia que a organização procura manter a tradição e respeitar seus costumes. $\mathrm{O}$ fator 4, "Bem-estar", composto pelas variáveis predominantes da mesma dimensão original, está relacionado à preocupação da organização em promover satisfação, bem-estar e qualidade de vida no trabalho. Por fim, o fator 5, "Conformidade", formado pelas variáveis predominantes relativas à mesma dimensão original, indica que a organização procura promover a correção, a cortesia e as boas maneiras no trabalho, bem como o respeito às normas internas.

Em relação às variáveis representantes da dimensão Preocupação com a Coletividade, proposta pelo modelo original, por não haver um agrupamento representativo dentro de nenhuma dimensão, ela não foi mencionada. Essa dimensão refere-se à promoção da igualdade, tolerância, sinceridade e honestidade dentro da organização. Entende-se que essas variáveis, apesar de não terem formado uma dimensão única, tiveram uma boa contribuição para a formação das dimensões encontradas. Ressalta-se que trabalhos como o de Andrade e Estivalete (2010) também agruparam variáveis distintas dos fatores originais, contudo, ao se analisar as assertivas observa-se a coerência dessas na formação dos fatores. Tal fato pode ter ocorrido devido ao pequeno número da amostra obtida, o que pode ser entendido como uma limitação desta pesquisa.

Depois de realizada a análise fatorial, foram analisadas as médias dos fatores dos valores organizacionais, a fim de classificá-los de acordo com sua importância (Figura 2).

Figura 2 - Médias e Desvio Padrão dos Fatores dos Valores Organizacionais

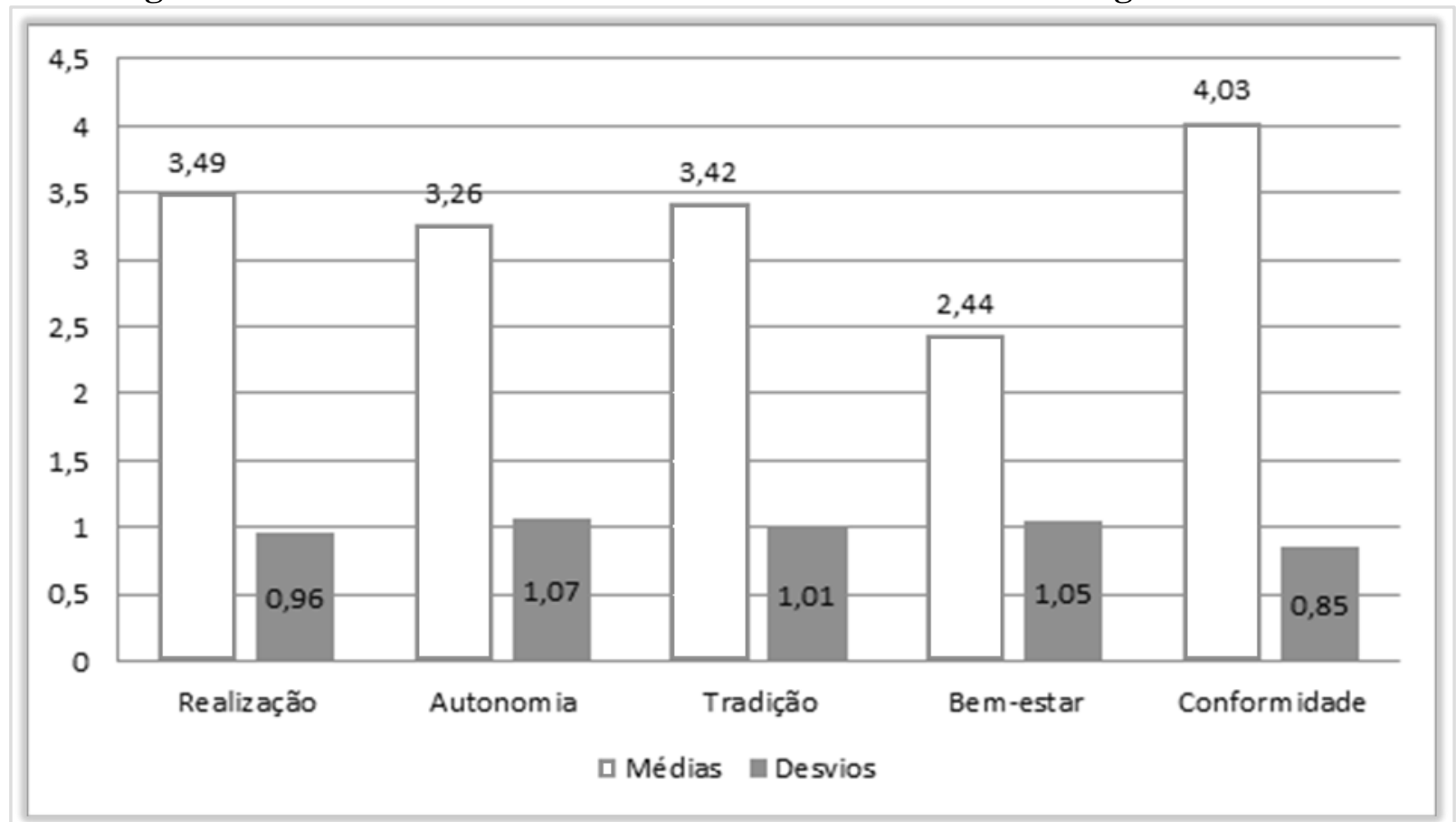

Fonte: Dados da pesquisa (2014)

Observa-se que, dos cinco fatores relativos aos valores organizacionais, os valores Conformidade (com média de 4,03), Realização (com média de 3,49) e Tradição (com média 3,42 ) representam os valores mais importantes na organização estudada, na percepção dos

GєCont, v. 3, n. 2, Floriano-PI, Jul-Dez. 2016. 
colaboradores. O resultado também confirma características empíricas de entidades públicas sem fins lucrativos, as quais ainda foram pouco estudadas sob a ótica dos valores organizacionais.

Por outro lado, os valores menos importantes na organização são Autonomia (com média de 3,26) e Bem-Estar (com média de 2,44). Em relação à Autonomia, associada aos interesses individuais (OLIVEIRA; TAMAYO, 2004), o valor pode ser explicado devido à resistência à mudança verificada na atuação do empregado e à importância atribuída ao valor Conformidade, que expressa o cumprimento às normas. Já o valor Bem-estar, considerado o menos importante, expressa o interesse pela satisfação e pela qualidade dos colaboradores e pode ser explicado devido ao seu uso não estratégico pelas entidades sem fins lucrativos. Além disso, o estatuto interno desse setor tem o interesse público com predominante sobre o interesse individual, o que contribui para que esse valor seja de baixa importância.

Os fatores obtidos refletem os valores organizacionais praticados pelo Tribunal de Contas, na percepção da amostra estudada, o que não é suficiente para generalizar os resultados para todo o setor de atividade daquela entidade. Ainda assim, sua hierarquização é de grande importância para o entendimento do clima organizacional da entidade e do comportamento dos servidores e também para identificar sua influência na percepção do Suporte Social, foco deste trabalho.

\subsection{PERCEPÇÃO DO SUPORTE SOCIAL NO TRABALHO}

Para analisar os dados coletados por meio da EPSST (Escala de Percepção de Suporte Social no Trabalho), utilizaram-se os mesmos procedimentos de análise fatorial exploratória aplicados no IPVO. A referida escala é composta por 18 variáveis que formam as dimensões dos suportes. O resultado do teste de Kaiser-Meyer-Olklin (KMO) foi de 0,876 e o teste de esfericidade de Bartlett apresentou um resultado de significância de (sig. 0,000), confirmando a adequação da análise fatorial para aquela amostra. As análises de medida de adequação da amostra e da matriz de correlação anti-imagem também foram satisfatórias. Ao se analisarem as comunalidades, uma variável precisou ser excluída, ficando todas com valores acima de 0,5 .

Executando a análise fatorial de componentes principais, foram obtidos quatro fatores com autovalores (eingenvalues) acima de 1,0, que juntos explicaram 68,75\% da variância total. Novamente, o critério a priori foi utilizado para a definição do número dos fatores, restando três, que correspondem à quantidade do instrumento original. Ao se aplicar o teste de confiabilidade Alfa de Cronbach aos fatores extraídos, todos apresentaram boa consistência interna, sendo que o fator 1 obteve como resultado o coeficiente de 0,909 , o fator 2 , um coeficiente de 0,882 e o fator 3 , um coeficiente de 0,712 .

Os três fatores obtidos representaram adequadamente as dimensões do instrumento EPSST original. Na Tabela 2, a seguir, são apresentados os fatores extraídos, bem como suas variáveis componentes e correspondências à escala original. As cargas fatoriais também foram apresentadas de acordo com sua classificação e importância para explicar a formação do fator.

Como apresentado na Tabela 2, o fator 1, que foi composto pelas variáveis predominantes referentes à dimensão Suporte Informacional do instrumento EPSST original, associa-se ao fornecimento de informações que auxiliam o indivíduo na solução de problemas diários ou no momento de tomar uma decisão. Esse suporte desenvolve no empregado crenças de que possui uma rede de comunicações que veicula informações precisas e confiáveis no ambiente de trabalho (GOMIDE JR.; SIQUEIRA, 2008). 
Tabela 2 - Composição dos fatores com as respectivas cargas obtidas com a rotação Varimax e fatores originais correspondentes

\begin{tabular}{|c|c|c|c|c|}
\hline Fator & Variáveis & Fator EPSST & Carga & Alpha \\
\hline \multirow{7}{*}{$\begin{array}{c}\text { Fator } 01 \text { - } \\
\text { Suporte } \\
\text { Informacional }\end{array}$} & $\begin{array}{l}\text { Informações sobre decisões que envolvem o trabalho que } \\
\text { realizam. }\end{array}$ & Informacional & 0,847 & \multirow{7}{*}{0,909} \\
\hline & $\begin{array}{l}\text { Superiores compartilham informações importantes com } \\
\text { servidores. }\end{array}$ & Informacional & 0,82 & \\
\hline & $\begin{array}{l}\text { Informações importantes para o trabalho são compartilhas } \\
\text { por todos. }\end{array}$ & Informacional & 0,79 & \\
\hline & $\begin{array}{l}\text { Informações circulam claramente sobre os setores da } \\
\text { organização. }\end{array}$ & Informacional & 0,75 & \\
\hline & $\begin{array}{l}\text { Informações importantes para o trabalho são repassadas } \\
\text { comagilidade. }\end{array}$ & Informacional & 0,723 & \\
\hline & Facilidade de acesso às informações importantes. & Informacional & 0,656 & \\
\hline & Pode-se confinar nos superiores. & Emocional & 0,61 & \\
\hline \multirow{6}{*}{$\begin{array}{l}\text { Fator } 02 \text { - } \\
\text { Suporte } \\
\text { Emocional }\end{array}$} & As pessoas são amigas umas das outras. & Emocional & 0,799 & \multirow{6}{*}{0,882} \\
\hline & \begin{tabular}{|l}
$\begin{array}{l}\text { As pessoas podem compartilhar com outros seus } \\
\text { problemas pessoais. }\end{array}$ \\
\end{tabular} & Emocional & 0,769 & \\
\hline & As pessoas se preocupam umas comas outras. & Emocional & 0,703 & \\
\hline & As pessoas gostamumas das outras. & Emocional & 0,698 & \\
\hline & Pode-se confiar nas pessoas. & Emocional & 0,541 & \\
\hline & $\begin{array}{|llll|}\begin{array}{l}\text { Há recompensas financeiras pelos esforços dos } \\
\text { servidores. }\end{array} & & \\
\end{array}$ & Instrumental & 0,427 & \\
\hline \multirow{4}{*}{$\begin{array}{l}\text { Fator } \mathbf{0 3} \text { - } \\
\text { Suporte } \\
\text { Instrumental }\end{array}$} & Equipamentos necessários para desempenhar as tarefas. & Informacional & 0,871 & \multirow{4}{*}{0,712} \\
\hline & Equipamentos emboas condições de uso. & Instrumental & 0,788 & \\
\hline & Salários compatíveis aos esforços dos servidores. & Instrumental & 0,55 & \\
\hline & Cumprimento das obrigações financeiras com servidores. & Instrumental & 0,487 & \\
\hline
\end{tabular}

Fonte: Dados da pesquisa (2014)

O fator 2, denominado "Suporte Emocional", composto pelas variáveis predominantes da mesma dimensão do modelo original, relaciona-se às expressões que provocam no indivíduo sentimento de carinho, cuidado e preocupação para com outro (GOMIDE JR.; SIQUEIRA, 2008). Tais sentimentos geram crenças no colaborador de que existem pessoas em quem se pode confiar, que se mostram preocupadas, se valorizam e gostam umas das outras. Já o fator 3, composto pelas variáveis predominantes da dimensão Suporte Instrumental do modelo original, refere-se às ajudas tangíveis ou práticas que a organização pode prover ao colaborador, como crenças de que a instituição o provê de insumos materiais, financeiros, técnicos e gerenciais necessários à execução do trabalho.

Ao se analisar as variáveis que formam os três fatores de Suporte Social no Trabalho, observou-se que os agrupamentos ficaram mais consistentes e mais representativos do modelo original, quando comparado ao IPVO. Poucas variáveis ficaram alocadas em dimensões diferentes do modelo original da escala EPSST, o que se configurou por haver um grande número de observações, comparando-se à quantidade de variáveis.

A média e o desvio-padrão podem ser observados na Figura 3, a seguir, o que permite claramente a classificação de importância dos tipos de suporte ofertados pela organização. Observando os dados do gráfico, percebe-se que o suporte de maior predominância é o Suporte Instrumental, com média de 3,94, o que pode ser explicado pela existência de um setor de TI (Tecnologia da Informação) altamente consolidado na organização, que sempre mantém os equipamentos em boas condições de uso. Nesse sentido, Mello (2008) ressalta que é necessário abrir espaço para a TI nas organizações para que se assuma um papel estratégico, principalmente, dando atenção às pessoas nesse processo. Contribui também o setor de Treinamento e Capacitação Continuada, que realiza cursos de capacitação e atualização 
periódicas para servidores, além da existência de uma política salarial baseada na produtividade.

Figura 3 - Médias e Desvio padrão das dimensões de Suporte Social no Trabalho

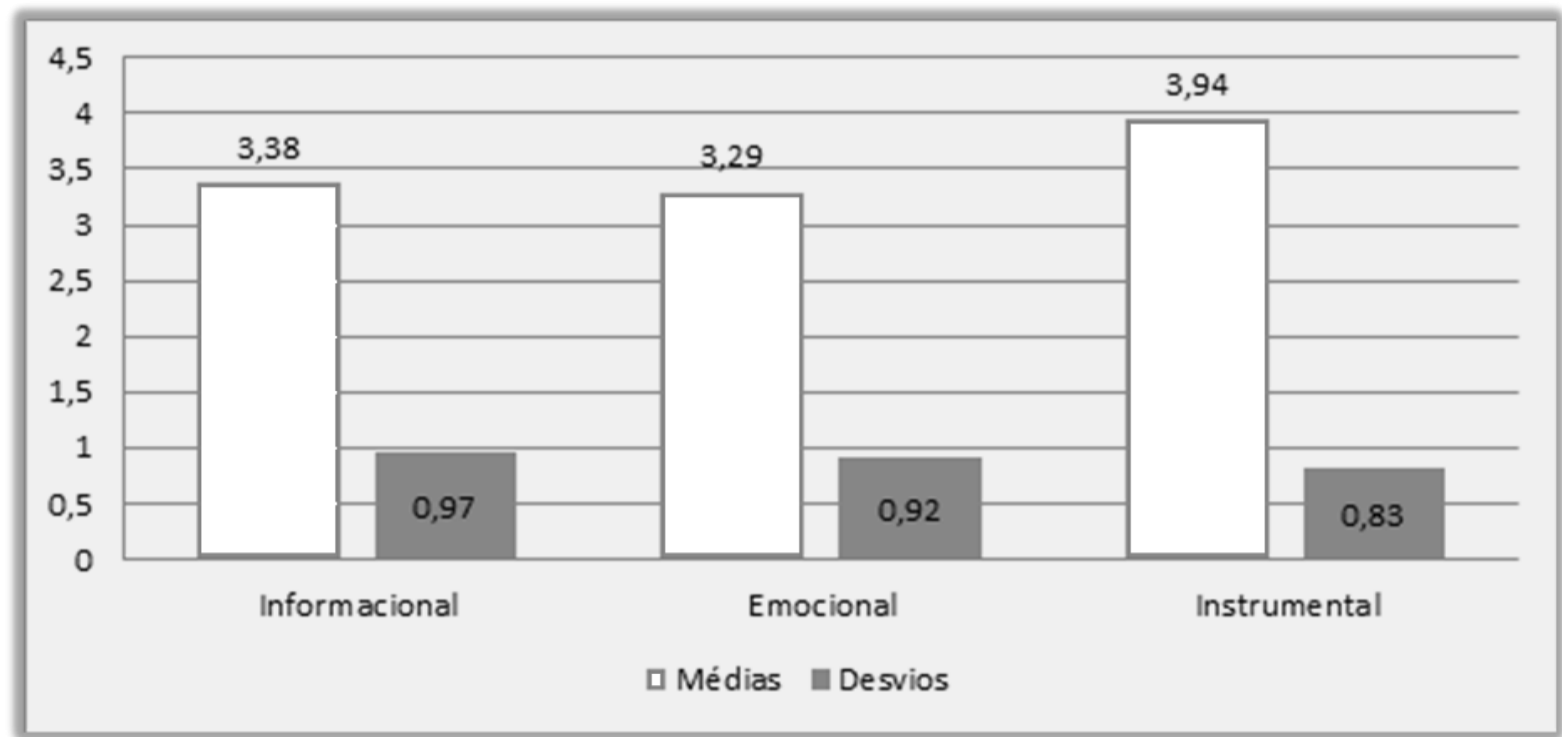

Fonte: Dados da pesquisa (2014)

Ainda sobre a Figura 3, o fator relativo ao Suporte Informacional foi o segundo mais representativo, com média de 3,38, seguido do Suporte Emocional, com a menor média de 3,29. Tal resultado reflete um baixo nível de relacionamento entre os colaboradores, o que pode ser uma informação relevante para o planejamento de ações para a melhoria do clima organizacional.

\subsection{VALORES ORGANIZACIONAIS COMO ANTECEDENTES DO SUPORTE SOCIAL NO TRABALHO}

Para verificar a influência dos Valores Organizacionais como precedentes da percepção do Suporte Social no Trabalho foram realizadas análises de regressão múltipla (Tabela 3) para identificar o quanto cada fator de Suporte Social no Trabalho (variável dependente) é explicado pelos fatores dos Valores Organizacionais (variáveis independentes).

$\mathrm{Na}$ estimação do modelo de regressão, foi usado o método de stepwise (por etapa), que permite examinar a contribuição de cada variável independente para o modelo de regressão. Nesse procedimento, de acordo com Hair Jr. et al. (2009), cada variável é considerada para inclusão antes do desenvolvimento da equação, sendo que a variável independente com maior contribuição é adicionada em primeiro momento, e as outras são selecionadas para inclusão com base nas suas contribuições incrementais sobre as variáveis já presentes.

Observa-se que dos cinco fatores dos valores organizacionais configurados como variáveis independentes, somente Realização, Autonomia e Conformidade apresentaram coeficientes beta significantes e capazes de serem considerados preditores do suporte social no trabalho (variáveis dependentes). Ressalta-se também que as variáveis representantes dos outros fatores não demonstrados na tabela não tiveram influência significativa positiva ou negativa na percepção do suporte social no trabalho. 
Tabela 3 -Valores da constante, coeficientes Beta, significância e coeficiente de determinação ajustado $\left(\mathbf{R}^{2}\right)$ para os modelos de regressão

\begin{tabular}{l|c|c|c|c|c|c|c|c|c}
\hline \multirow{2}{*}{$\begin{array}{c}\text { Variável dependente Suporte } \\
\text { Social no Trabalho }\end{array}$} & \multicolumn{2}{|c|}{ Constante } & \multicolumn{2}{c|}{ Realizac̃a } & \multicolumn{2}{c|}{ Autonomia } & \multicolumn{2}{c|}{ Conformidade } & \multirow{2}{*}{$\mathbf{R}^{2}$ Ajustado } \\
\cline { 2 - 11 } & Valor & Sig. & Coef. & Sig. & Coef. & Sig. & Coef. & Sig. & \\
\hline Informacional & 1,823 & 0,000 & & & 0,530 & 0,000 & & & 0,271 \\
\hline Emocional & 1,994 & 0,000 & 0,537 & 0,000 & & & & & 0,279 \\
\hline Instrumental & 1,807 & 0,000 & 0,366 & 0,003 & & & 0,262 & 0,028 & 0,285 \\
\hline Suporte Geral & 1,999 & 0,000 & 0,633 & 0,000 & & & & & 0,393 \\
\hline
\end{tabular}

Fonte: Dados da pesquisa (2014)

Os modelos propostos consideraram as variáveis Suporte Social Informacional, Emocional, Instrumental e Suporte Geral como variáveis dependentes, sendo que as variáveis independentes foram os fatores dos valores organizacionais, testados para cada modelo. As duas variáveis que tiveram influência significativa, conforme apresentado na tabela, foram de maneira positiva, indicando que quanto maior a prioridade daqueles valores, maior a percepção do Suporte Social.

Em uma análise detalhada das variáveis do Suporte Social, percebeu-se que, para a variável Suporte Social Informacional, a variável independente Autonomia teve influência positiva para explicar aquele suporte, o que indica que quanto maior a prioridade desse valor, maior será a percepção do Suporte Social Informacional. Esse resultado se assemelha aos encontrados por Andrade e Estivalete (2010), em um estudo realizado em instituições bancárias, para os quais esse valor também teve considerável influência para esse suporte. Para a variável Suporte Social Emocional, o fator Realização exerceu influência positiva para sua percepção. A variável Suporte Social Instrumental teve os fatores Realização e Conformidade exercendo influência positiva, sendo também considerada como preditora desse suporte. Observou-se também que a variável Realização teve a maior influência para a variável Suporte Geral, o que indica que, de maneira geral, esta variável é a que exerce influência predominante na percepção do Suporte Social percebido naquela organização. Os resultados para todos os modelos, considerando os valores testados, se assemelham aos encontrados por Andrade e Estivalete (2010) e corroboram - neles, as variáveis Autonomia e Realização tiveram as maiores influências na percepção do Suporte Social no Trabalho.

Analisando o coeficiente de determinação ajustado $\left(R^{2}\right)$, percebeu-se que todos os valores dos modelos de regressão apresentaram boa contribuição para explicar as variáveis de Suporte Social. Para Hair Jr. et al. (2009), os valores de $\mathrm{R}^{2}$ variam entre 0 e 1 , sendo que quanto maior forem, melhor a previsão da variável dependente. Nesse sentido, nota-se também que o fator Realização explica 39,30\% da variância total da dimensão Suporte Social (Suporte Geral).

Durante as análises, foram testados pressupostos para os modelos de regressão estimados. Primeiramente, foi verificada a normalidade dos modelos através do teste de Kolmogorov-Smirnov, que devolveu valores superiores a 0,05 , indicando que os modelos seguem uma distribuição normal. Em seguida, o teste de Durbin-Watson foi aplicado para verificar a independência dos resíduos da regressão. Em todos os modelos, verificou-se que os resultados não foram significativos, indicando que os erros não são independentes. Por fim, o pressuposto da homocedasticidade foi verificado no teste de Pesaran-Pesaran, que faz uma regressão entre os resíduos quadráticos (variáveis independentes) e os preditos (variáveis dependentes): se a regressão não for significativa, há a homocedasticidade (Hair Jr. et al., 2009). Todos os modelos atenderam aos pressupostos da homocedasticidade.

Após as análises e validações dos modelos estimados, pôde-se confirmar a influência de alguns valores organizacionais na percepção do Suporte Social na organização estudada. Os resultados podem ser utilizados para a compreensão da cultura e do clima organizacional, 
os quais impactam na qualidade de vida dos servidores, assim como no seu desempenho na organização (FERREIRA, 2013).

\section{CONSIDERAÇÕES FINAIS}

A pesquisa buscou identificar qual a influência dos valores organizacionais na percepção do Suporte Social no trabalho, sob a perspectiva dos colaboradores do TCE-RO. Considerando os valores organizacionais estudados, verificou-se que os valores predominantes na organização foram Conformidade e Realização, seguidos de Tradição. Esses resultados, além de serem potencialmente úteis para os gestores, podendo contribuir para o diagnóstico e planejamento do processo de mudança, conforme Oliveira e Tamayo (2004), também confirmam características empíricas verificadas em instituições da administração pública. Já os valores Autonomia e Bem-estar foram os que tiveram menor importância, o que revela pouco interesse por parte da organização em relação aos interesses individuais de seus servidores. Esse resultado confirma a concepção de que, nas instituições da administração pública, o interesse público predomina sobre o individual, tornando, assim, esses valores hierarquicamente menos importantes.

$\mathrm{Na}$ análise do Suporte Social, observou-se que o Suporte Instrumental foi o de maior relevância, demonstrando que o colaborador sente-se provido de insumos materiais, financeiros, técnicos e gerenciais necessários ao desempenho do seu trabalho. Constatou-se também, na análise das cargas fatoriais das assertivas desse suporte, que o papel da TI foi de grande importância para a sua percepção. Isso ressalta a importância da TI para resolver questões estratégicas da organização, visando ao alcance do sucesso, conforme Melo (2008).

Os resultados corroboram com os encontrados por Andrade e Estivalete (2010) em seus estudos, nos quais os valores Autonomia e Realização refletem maior influência na percepção do Suporte Social no Trabalho. Em relação à análise dos valores organizacionais como precedentes do Suporte Social, verificou-se, na análise de regressão múltipla, que os valores Autonomia, Realização e Conformidade exerceram influência positiva na percepção do Suporte Social. Quanto ao Suporte Informacional, a variável significativamente influente foi Autonomia. O Suporte Instrumental obteve as variáveis Realização e Conformidade exercendo influência significativa. Já os Suportes Emocional e Geral tiveram o fator Realização exercendo tal influência.

Além disso, o estudo dos Valores Organizacionais contribui para o diagnóstico e compreensão da cultura organizacional da instituição, bem como o Suporte social contribui para a compreensão das condições de trabalho. Estando ambos ligados ao clima organizacional que, segundo Ferreira (2013), impacta as satisfações com o trabalho, a interação entre grupos e comportamentos dos servidores é de grande importância para a criação de um ambiente de trabalho adequado, com maior produtividade.

Ressalta-se, neste trabalho, que, como contribuição teórica, tem-se a análise da relação entre Valores Organizacionais e Suporte Social na administração pública e, como contribuição prática, a avaliação da influência dos valores na percepção do Suporte Social para ajudar os gestores públicos em suas diversas ações. A utilização dos resultados apresentados pode orientar o desenvolvimento do trabalho e planejamento do setor de Gestão de Pessoas do TCE-RO.

Como limitação, tem-se o tamanho da amostra, que diminui a precisão das análises estatísticas, bem como a subjetividade dos tipos de análises aplicadas e o fato de não se ter avaliado todos os valores propostos por Oliveira e Tamayo (2004). Ressalta-se também que as observações não podem ser generalizadas para todo o setor público, como as empresas públicas pertencentes à administração indireta, tendo em vista que os objetivos da 
administração pública governamental são diferentes dos das entidades públicas com fins lucrativos.

Desse modo, sugerem-se outras pesquisas em entidades do setor público sobre a qualidade de vida e Suporte Social, bem como uma replicação da pesquisa em outras organizações do controle externo a fim de comparar os resultados aqui obtidos. Outro teste a ser considerado é o da ANOVA, para verificar se os fatores Valores Organizacionais produzem mudanças sistemáticas em alguma variável do Suporte Social no trabalho (variável dependente).

\section{REFERÊNCIAS}

ANDRADE, T.; ESTIVALETE, V. F. B. Valores Organizacionais e Suporte Social no Trabalho:a percepção dos colaboradores do setor bancário público e privado. In: XXXIV Encontro da Associação Nacional de Pós-graduação em Administração, Anais... Rio de Janeiro: ANPAD, 2010.

BERGUE, S. T. Gestão estratégica de pessoas no setor público. São Paulo: Atlas, 2014.

COBB, S. Social support as a moderator of life stress. Psychosomatic Medicine, v. 38, n. 5, p. 300-3014, set./out. 1976 .

COHEN, S. Social Relationships and Health. American Psychologist, v.11, p. 676-684, 2004.

COHEN, S; MCKAY G. Social Support, Stress and the Buffering Hypothesis: A Theoretical Analysis. In: A. Baum, S.E. Taylor, \& J.E. Singer (Eds), Handbook of Psychology and Health. Hillsdale, NJ, 1984.

CHOR, D. et al. Medidas de rede e apoio social no Estudo Pró-Saúde: pré-testes e estudo piloto. Cadernos de Saúde Pública, v. 17, n. 4, 887- 896, 2001.

CORRAR, L. J. et al. Análise multivariada: para os cursos de administração, ciências contábeis e economia. São Paulo: Atlas, 2011.

DEAL, T E; KENNEDY, A. A. Corporate Cultures: The Rites and Rituals of Corporate Life, Reading MA: Addison Wesley, 1982.

ESTIVALETE, V. F. B. et al. Valores Organizacionais como antecedentes do suporte do trabalho: uma análise no setor bancário público estadual e federal. In: XXXIV EnAPG Encontro de Administração Pública e Governo, Anais... Salvador: ANPAD, 2012.

FERREIRA, P. I. Clima organizacional e qualidade de vida no trabalho. Rio de Janeiro: LTC, 2013.

FIGUEIREDO FILHO, D. B.; SILVA JR, J. A. Visão Além do Alcance: uma introdução à análise fatorial. Opinião Pública, Campinas, v. 16, n. 1, jun., p. 160-185, 2010.

GOMIDE JR., S.; GUIMARÃES, L. C.; DAMÁSIO, L. F. Q. Construção e validação de um instrumento de medida de percepção de suporte social no trabalho. II Seminário de Pesquisa do Grupo Interinstitucional de Pesquisa em Bem-estar e Suporte Social e Trabalho, Anais... Uberlândia, 2004.

GOMIDE JR, S.; SIQUEIRA, M. M. M. Suporte no Trabalho. In: SIQUEIRA, M. M. M. (org). Medidas do comportamento organizacional. Porto Alegre: Artmed, 2008.

HAIR JR., J. F. et al. Análise multivariada de dados. Tradução Adonai Schlup Sant'Anna.

GєCont, v. 3, n. 2, Floriano-PI, Jul-Dez. 2016. 
6. ed. Porto Alegre: Bookman, 2009.

MARCONI, M. A.; LAKATOS, E. M. Técnicas de pesquisa: planejamento e execução de pesquisas, amostragem e técnicas de pesquisa, elaboração, análise e interpretação de dados.

7. ed. São Paulo: Atlas, 2009.

MARTINS, G. de A.; THEÓPHILO, C. R. Metodologia da investigação científica para ciências sociais aplicadas. 2. ed. São Paulo: Atlas, 2009.

MELO, D. R. A. A importância da tecnologia da informação nas estratégias das organizações contemporâneas: breve revisão de literatura. V Convibra, 2008.

OLIVEIRA, A. de F.; TAMAYO, A. Inventário de Perfis de Valores Organizacionais. Revista de Administração, São Paulo, v. 39, n. 2, p.129-140, 2004.

RODRIGUEZ, M. S.; COHEN, S. Social support. Encyclopedia of mental health. New York: Academia Press, v. 3, 1998.

SCHWARTZ, S. H. Universals in the content and structure of values: Theory and empirical tests in 20 countries. In M. Zanna (Ed.), Advances in experimental socialpsychology, v. 25, p. 1-65, 1992.

SEEMAN, T. E. Social Support and social conflict.2008.Disponível em:

<http://www.macses.ucsf.edu/research/psychosocial/socsupp.php>. Acesso em: 06 ago. 2014.

SIQUEIRA, M.M.M.; PANDOVAM V.A.R. Bases teóricas de bem-estar subjetivo, bem-estar psicológico e bem-estar no trabalho. Psicologia: Teoria e Pesquisa, v. 24, n. 2, p. 201-209, 2008 .

TAMAYO, A. Valores organizacionais e comprometimento afetivo. Revista de Administração Mackenzie.Ano 6, n.3, p. 192-213, 2005.

. Valores organizacionais: sua relação com satisfação no trabalho, cidadania organizacional e comprometimento. Revista de Administração da Universidade de São Paulo (RAUSP), São Paulo, v.33, n.3, p. 56-63, jul./set. 1998.

.Valores Organizacionais. In: SIQUEIRA, M. M. M. Medidas do comportamento organizacional. Porto Alegre: Artmed, 2008.

TAMAYO, A.; MENDES, A.M.; PAZ, M. G. T. Inventário de Valores Organizacionais. Estudos de Psicologia. v. 5, n.2, p. 289-315, 2000.

TAMAYO, A.; GONDIM, M. G. C. Escala de Valores Organizacionais. Revista de Administração,v. 31, n. 2, p. 62-72, 1996.

TEIXEIRA, M. L. M. Valores humanos e gestão: novas perspectivas. São Paulo: Editora Senac, 2008.

VIEIRA, M. S. O. C.; GOMES, D. C. Valores Organizacionais numa instituição pública de ensino do RN. Holos, ano.29, v. 3, p. 77-89, 2013.

GєCont, v. 3, n. 2, Floriano-PI, Jul-Dez. 2016. 